INTERNATIONAL JOURNAL OF RESEARCHES IN BIOSCIENCES, AGRICULTURE AND TECHNOLOGY (C) VISHWASHANTI MULTIPURPOSE SOCIETY (Global Peace Multipurpose Society) R. No. MH-659/13(N) www.vmsindia.org

\title{
EMBRYONIC DEVELOPMENT OF ENDOCRINE GLANDS IN JAPANESE QUAIL, COTURNIX COTURNIX JAPONICA
}

\author{
Jyoti Ramteke ${ }^{1}$ and Pravin Charde ${ }^{1}$ \\ Se vadal Mahila Mahavidyalaya, Nagpur-440024 (M.S.)
}

\section{Abtract}

The experiment was conducted to study the development of Endocrine Glands in quail embryos. The eggs of Japanese Quail are incubated in BOD incubator at $35^{\circ} \mathrm{C}$ and $60 \%$ Relative Humidity. The embryos were cut out, fixed, paraffin sectioned and stained with Heamatoxylene-Eosin. The result shows that the formation of ovaries starts from 4th day of incubation. It matures till $17^{\text {th }}$ day of incubation. The testis starts developing by showing the epididymal linings on $5^{\text {th }}$ day. The adrenal gland starts developing from $4^{\text {th }}$ day as the triangular portion above kidney can be differentiated on $6^{\text {th }}$ day. Thyroid gland appears as out growth from $4^{\text {th }}$ day but it is visible on $8^{\text {th }}$ day of incubation. These results established the basic groundwork for the research of the de velopment of other e ndocrine glands of quail as well as other poultry.

Ke ywords: Incubation, De ve lopmental stages, Embryology, Endocrine Glands and Hormones.

\section{Introduction}

Embryology is the science of development of the individual during the embryonic stage and subsequent stages of the life cycle. Chick e mbryo proceeds from egg lying to having a functional heart within 36 hours. Obtaining embryos does not require the death of the mother as in the case of mice and rats.

Endocrinology is the study of endocrine system and its role in the physiology of the body. Avian endocrine system includes Pituitary gland, Gonads, Thyroid gland, Parathyroid gland, Adrenal gland, Pineal bodies and Thymus gland. The Gonads, Adrenal gland and Thyroid gland are under the control of Ante rior Pituitary gland which is considered to be the master gland. The sex organs of males and females are called the Gonads. These organs produce hormones namely Oestrogen, Testosterone and Progesterone. Both male and female need all three hormones but in diffe re nt amounts. The Thyroid gland consists of two reddish purple glands lying one on each side of the base of the neck. This gland produces two hormones: (1) Thyroxine, which helps regulate heat production, carbohydrate metabolism, promotes high blood sugar level and promotes growth. (2) Thriiod othyronine for developme nt of skin and feathers. The Adrenal glands are small glands approximately $9 \mathrm{~mm}$ long located anterior to or in front of the kidneys. These are such glands, each associated with a particular kidney. Each gland consists of two diffe rent types of cells that form two dis tinct parts of the gland - adrenal cortex and adrenal medulla.

Quail, Coturnix coturnix, belongs to Aves, Galliformes,Phasianidae and Coturnix bonnaterre. It has been widely studied in the fields of developmental and reproductive biology as a usual kind of experimental animal model. Now domes tic studies about raising quails scientifically have been reported in detail $(\mathrm{Hu}$, 1990), while reports on development of quail's embryo and gonad are few. Diffe rentiation and development processes of poultry gonads are similar to other vertebrates. Both are differentiated into testis and ovary from gonads in which there are no morphological diffe rences. Gonadal differentiation generally occurs on the 5 - 7 th day of hatching and gonads differentiate completely on the 8 th - 10th day of hatching so that we can identify the sex of them anatomically. In this experiment, quail's embryos of 4 to 17 days and the day one of quail hatching we re used as the objects of study and then they were observed for the time of differentiation of endocrine glands and a series of morphological development. The results provided basis for the differentiation and development mechanisms of endocrine glands in quails and other birds.

\section{Materials and Methods:}

\section{Sample collection}

Quail's hatching eggs used in the study were from Venkateshwara Hatchery, Pune. The eggs we re incubated in BOD incubator after fumigation. The temperature of incubator is set up to $38^{\circ} \mathrm{C}$ and humidity at $60 \%$.

\section{Embryo collection}

Embryo collection on the 4 - 6th day of hatching: the blunt end of the incubated egg was gently knocked out with ophthalmic forceps, the shell and shell membrane were removed; the embryo was transferred into Petridish filled with warm $\left(38-39^{\circ} \mathrm{C}\right) 0.75 \%$ saline with the help of forceps; embryo sac and the outer membrane surrounding the embryo were cut off and then the embryo was rinsed with clean warm $0.75 \%$ saline gently for $2-3$ times. Finally, the embryo was soaked in Bouine's fixative labeling with date of sample, egg weight, and embryo weight for ove rnight. 


\section{Results and Discussion: Quail gonads}

On the 5th day Gonads began to differentiate in this period, serial sections showed that the development of mesonephros was obvious and could be clearly observed. Mesonephros was separated distinctively with germanium which enlarged and extruded inside the mesonephros. There were sections showed that ovarian-like germanium which seemed to be divided into cortex and medulla was shaped like strips. At this stage, germanium had the morphological characteristics of ovarian development, so we could re name it as gonad.

On the 7 th day Sections of this period showed that there had been significant features of ovarian biopsy. Both the left and right ovaries was smooth like strips, but the left ovary slightly longer than the right ovary while testis was clearly not the same with it. Under the microscope observation, the re were no significant differences between cortex and medulla, and oogonium characte rized by large cell and nuclear began to emerge. In this stage, mesonephros degraded slowly and metanephros be gan to form.

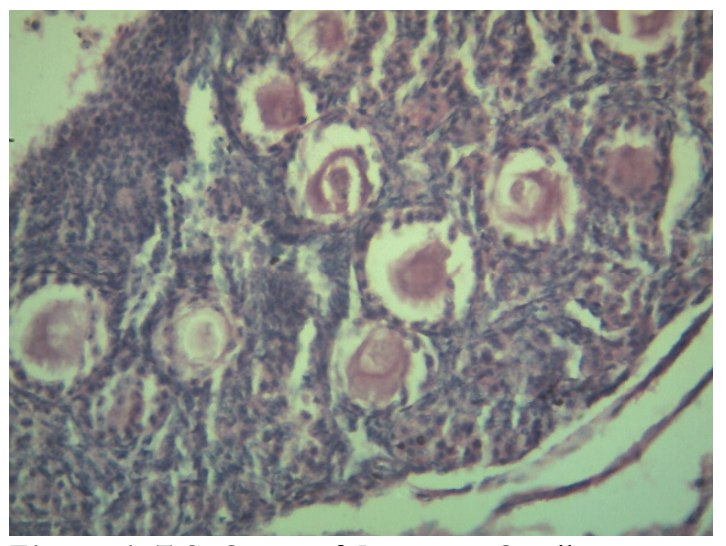

Figure 1: T.S. Ovary of Japanese Quail.

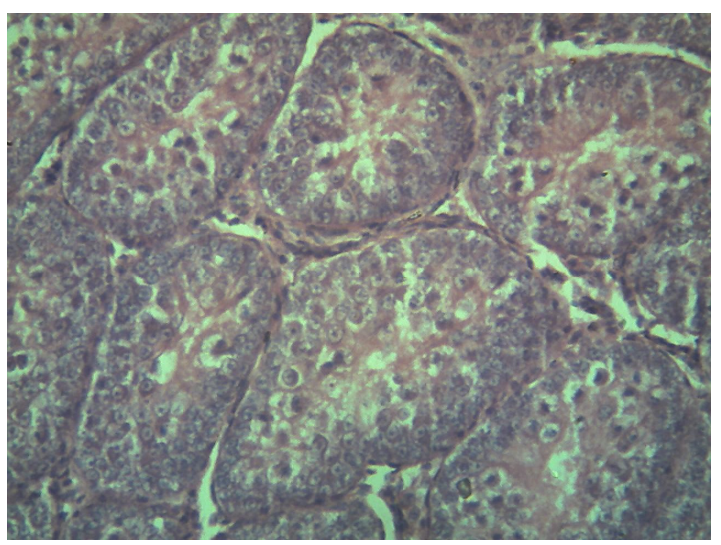

Figure 2:T.S. Testis of Japanese Quail.

\section{Quail Adrenal gland}

It has been found that the quail e mbryo adrenal glands can secrete corticoids from the 5th day onwards. The adrenal develops from the 8th day is significantly correlated with the secretory capacity of the gland. and increases steadily up to the 10th day. The re are sections which show the adrenal cortex and medulla on $8^{\text {th }}$ day of embryo.

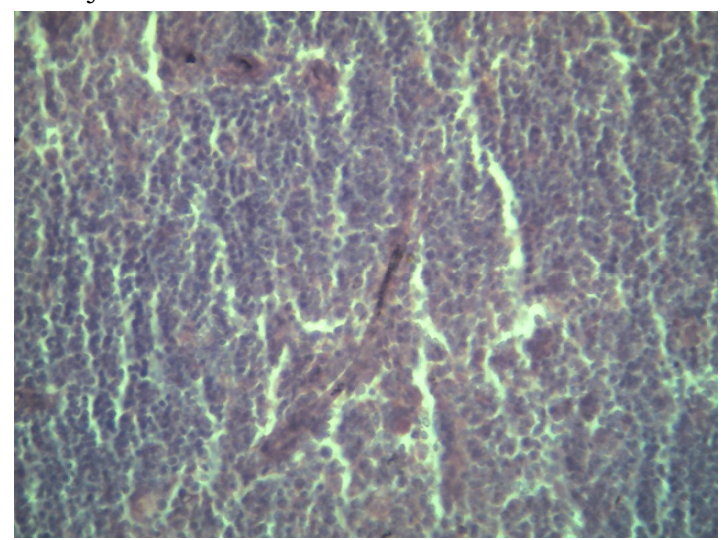

Figure 3: T.S. Adre nal Gland of Japanese Quail. $Q$ uail Thyroid gland

The Thyroid gland arises from the floor of the pharynx as a diverticulum. At the end of the $4^{\text {th }}$ day of incubation the thyroid evagination retains its connection with the pharynx.The study showed that on the 4 th day of hatching, The gonadal differentiation had not begun on the 4 th day. On the 5 th day of hatching, the gonads began to differentiate and had an initial emergence of the characteristics of the testis or ovary and on the 7 - 10th day; the sex diffe rence was very obvious that the right ovary degraded gradually while the left developed naturally.

The gonadal differentiation of the chicken embryo began on the 6 th day of the incubation period and this kind of differentiation became more significant on the 7 th day. This may be associated with quail's shorter incubation period, in other words, quail's embryonic development was slightly faster than chicken's, so the go nadal differentiation also began e arlier than chicken. In addition, the incubation temperature setting mainly referred to the hatching process of chicken. And under the same volume, the number of quail eggs was higher, so the actual incubation temperature is relatively high, which to some ex te nt, also promoted the development of quail e mbryos. 


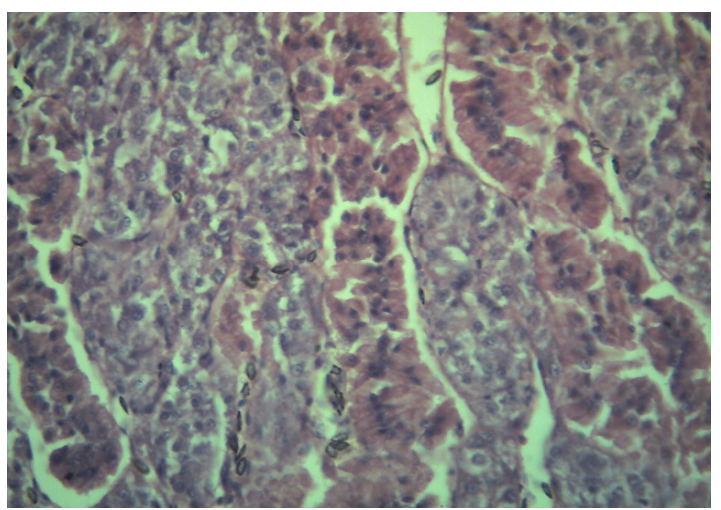

Figure 4: T.S. Thyroid Gland of Japanese Quail Conclusions:

The above results concludes the mechanisms of the endocrine development of quails, chickens and other poultry, these could be analyzed through the migration in the embryo period to study the genuine processes of development of endocrine gland, and provide a new basis for the poultry developmental biology. The endocrinological study have provided us with a wealth of information on the differentiation and maturation of endocrine glands, the anatomical and functional development, ontoge nic changes in the responsiveness and activity of the glands and the ir target organs, and the interactions of different regulatory systems to coordinate developmental processes such as hatching .The Endocrine syste $\mathrm{m}$ cons is ts of various glands and nodes which secrete hormones. The importance of these hormones (which are chemical messengers) lies in the fact that they travel in the blood to activate target cells. These target cells have special receptors, into which only certain hormones can fit. For example, testos te rone acts on the male go nads, but not the adrenal glands. In view of the importance of endocrine glands, their (endocrine gland's) development in Japanese quail was assessed on the basis histological studies. The slides were prepared from the sections of embryo ofe ach day. Serial sections were studied. The specific findings with respect to the development of endocrine glands in Japanese quail is as follows

- Adrenal Gland: These are a pair of small glands, some $9 \mathrm{~mm}$ long, located in front of the kidneys. In the Japanese quail, the adrenal glands appeared in the $4^{\text {th }}$ day embryo.
- Ovary: Ovary formation appeared in the $5^{\text {th }}$ day embryo.

- Testis: Testis were observed in the $4^{\text {th }}$ day embryo.

- Thyroid: Thyroid gland formation observed in the $6^{\text {th }}$ day embryo.

\section{References:}

1) Al-Tememy, HAS. (2010). Histological study of te stis in Quail (Coturnix coturnix japonica), Al-Anbar J. Vet. Sci, 3(2), pp. 36-44

2) Avian adre nal medulla: cytomorphology and function - Ashok Ghosh, Stephen W. Carmichael, Monisha Mukherjee, Act A Biologica Szegediensis, 2011, 45(1-4), pp. 111

3) Bonaminio, G.A. \& Fechheimer, N.S. (1993). The gonadal histology of triploid chicken (Gallus domesticus) e mbryos, Genet Sel Evol, 25, pp. 205-210

4) De Groef, B., Grommen, SVH. \& Darras, VM. (2008). The chicken embryo as a model for developmental e ndo crinology: de velopment of the thyrotropic, corticotropic, and somatotropic axes, Molecular and Cellular Endocrinology, 293, pp. 1-2

5) Endocrinology of the Avian Reproductive system (1995) Mary and Ottigen and Murray R. Bakst Publications from USDA-ARS/UNL faculty.

6) Histological study of testis in Quail (Coturnix Coturnix Japonica) - H.S. A Al- Te mery, AlAnbar J Vet.Sci., Col: 3 no.(2), 2010, pp. 3644

7) Ottinger M.A. \& Bakst M.R. (1995). Endocrinology of the Avian Reproductive System, Publication from USDA-ARS/UNL faculty.

8) Ozegbe, P.C., Aire T.A. \& Soley J.T. (2006). The morphology of the efferent ducts of the testis of the ostrich, a primitive bird. Anatomy and Embryology, 21 1(5), pp. 559-65.

9) Rong C., Guobin C., Yurong Q., Bichun L. \& Guohong C. (2011), The develo pment of ovary in quail's embryo, African Journal of Biotechnology, 10 (4), pp. 712-717

10) Scanes S. G., Hartle, Decuypere E. \& Kuhn E.R. (1987). Endocrinology of the Avian embryo; an overview. J Exp Zoo suppl, 1, pp.253-64. 